\title{
Escribir el morir, escribir el matar sudamericanos
}

La Cuenca del Plata desde El Matadero (1838) hasta "El Caso Maldonado" (2018)

Écrire la mort, écrire le meurtre en Amérique du Sud. Le bassin du rio de la Plata depuis L'abattoir (1838) jusqu'à « L'affaire Maldonado » (2018).

\section{Alfredo Grieco Y Bavio}

\section{OpenEdition}

Journals

\section{Edición electrónica}

URL: https://journals.openedition.org/agedor/6065

DOI: $10.4000 /$ agedor.6065

ISSN: 2104-3353

\section{Editor}

Laboratoire LISAA

\section{Referencia electrónica}

Alfredo Grieco Y Bavio, «Escribir el morir, escribir el matar sudamericanos», L'Âge d'or [En línea], 13|

2020, Publicado el 11 octubre 2021, consultado el 14 octubre 2021. URL: http://

journals.openedition.org/agedor/6065 ; DOI: https://doi.org/10.4000/agedor.6065

Este documento fue generado automáticamente el 14 octubre 2021.

L'Âge d'or. Images dans le monde ibérique et ibéricoaméricain 


\title{
Escribir el morir, escribir el matar sudamericanos
}

\author{
La Cuenca del Plata desde El Matadero (1838) hasta "El Caso Maldonado" \\ (2018) \\ Écrire la mort, écrire le meurtre en Amérique du Sud. Le bassin du rio de la Plata \\ depuis L'abattoir (1838) jusqu'à « L'affaire Maldonado » (2018).
}

\author{
Alfredo Grieco Y Bavio
}

Para Isaac Behar y Lisa Block de Behar para siempre

1 La literatura de ficción de la Cuenca del Plata independiente escrita en lengua castellana nace toda entera con un texto de la mayor urgencia política y militante: en armas, según la clásica imagen canónica helénica antigua de Palas Atenea saliendo de la dolida testa de Zeus, ese Monsieur Teste (Don Cacumen, según Borges y Bioy Casares en Borges $^{1}$ ) por tradicional excelencia. $Y$ es un texto de máxima, acaso insuperada calidad canónica: la nouvelle El Matadero ${ }^{2}$ de 1838 publicada recién en 1871 . Su autor, el poeta Esteban Echeverría, había logrado unos años antes con su epopeya femenina Elvira o la novia del Plata ${ }^{3}$ que el romanticismo francés cruzara con más urgente prontitud el océano Atlántico que los montes Pirineos. La versión literaria del liberalismo político había llegado antes al porteño río de la Plata que al madrileño arroyo Manzanares.

2 La literatura de ficción en prosa sudamericana lograba así su incipit en un relato desembozadamente costumbrista, pero potente, poderoso en su sobrio realismo crítico, de la violación masculina de un hombre por varios hombres en patota, un gang rape político seguido de muerte. En esta nouvelle de Echeverría, en la carnívora y carnicera Confederación Argentina que fue, según la oposición unitaria, la larga 'tiranía' del federal Juan Manuel de Rosas, peones populares y populistas, fieles hasta la adicción a este tirano tradicional, clerical, hispanizante y poscolonial que se presentaba como Restaurador de las Leyes, violan a un joven intelectual, liberal, europeizante, laico y democrático. 
Durante dos siglos, un principio constructivo literario inherente a esta matriz de narrativa política nacional, con su sistema de nítidas oposiciones hegemonizará toda la región con una monotonía que sólo ha vuelto indetectable el brillo y mérito que al principio fueron raros y después únicos de esa literatura.

4 En el llamado "Caso Maldonado" ${ }^{4}$, un hecho policial que sirvió del más abundante disparador para narrativas irreconciliablemente enfrentadas en la Argentina de hoy y aun en la región, era asombroso, pero no debería resultarnos a estas alturas sorprendente, el parecido físico y moral entre el joven demócrata de 1838 - en el proyectamos la imagen real del escritor Echeverría o al menos la que corresponde a la retratada en su clásico cuadro - y el joven demócrata de 2017. Uno y otro son varones jóvenes, barbados, solteros, delgados, pobres pero dignos, militantes socialistas en un contexto nacional institucional represivo. Uno y otro mueren por vencer la regla clasemediera rioplatense en general pero porteña en especial del "no te metás". El unitario se mete entre los gauchos (federales, i.e. enemigos en la guerra civil), Santiago entre los indios (mapuches, i.e. sus amigos adoptivos en una guerra étnico-clasistacultural para los que sin embargo la adopción es menos simétrica de lo que él cree). En ninguno de los dos casos hay duda sobre la víctima. En la nouvelle de Echeverría tampoco hay duda sobre los victimarios, porque está escrita desde un exilio que anticipa (con acierto) que la victoria final será del partido de la víctima, y no del victimario. En cambio, en el caso Maldonado, la lucha a muerte ha sido por determinar quién es el victimario, y las posiciones son tan irreconciliables como es incierta, a esta hora, a cuál tocará la victoria final, o próxima.

Del argentino Borges al franco argentino Cortázar, o de los uruguayos Benedetti y De Mattos, el canon artístico consensuado parece que nunca hubiera desfallecido en elegir como predilecta alguna variante de esta matriz. Que podía modificarse en parte o cambiarse en un todo, en un giro absoluto, a quién tocara, en cada caso, el signo positivo. Así como la forma no se veía alterada, tampoco se desplazaban ni el punto de vista, ni la voluntas retórica de la empatía. Ningún lector podía ni dudarlo ni, si contaba con la competencia literaria suficiente - es decir, en este caso, mínima - podía ignorarlo. Sin fundar en ello ni su especificidad ni su legitimidad, estas literaturas, estas narraciones daban vox publica a quienes no tenían voz siquiera privada, porque sus gargantas habían sido tronchadas. Los relatos prestaban su voz in praesentia a las víctimas in absentia.

6 No sólo se ha retenido, casi dos siglos después, la identidad en las formas de este curso mayor de la narrativa. Ha podido mudar radicalmente la materia (a quién toca cada papel antagónico en la historia), pero ni el sentido ni la moraleja: la positividad toca a quien le toque el lugar de la víctima.

7 A esto se han unido rasgos históricos, singulares, contingentes, que no tenían por qué verse unidos, a priori, con aquella matriz narrativa. Mencionaré sólo dos:

8 1) El primero de estos rasgos es la soledad e individualidad de la víctima, con rasgos personales que lo humanizan (el masculino es deliberado), frente al carácter grupal, colectivo, anónimo de los victimarios. La víctima luce más moderna, los victimarios más retardatarios. Pero no es la lucha del individuo frente a las masas. Al contrario, la víctima representa a la sociedad, no a la comunidad. Más precisamente, a una vanguardia política que asume una posición revolucionaria o reformista, frente al corporativismo. Desde el punto de vista de la trama, se da respuesta a una objeción razonable. No es que la víctima represente a la 'bella alma' hegeliana, a una posición 
débil y antipopular, sino que se abusan de él porque lo han encontrado sólo y sus acosadores, que se han topado con él, o lo han emboscado, son muchos. Como en el romance del granadino García Lorca, "Muerte de Antoñito el Camborio": "en la lucha daba saltos /jabonados de delfín, / pero eran cuatro puñales / y tuvo que sucumbir"

9 En "La fiesta del monstruo", , relato antiperonista compuesto por los argentinos Borges y Adolfo Bioy Casares pero publicado prudentemente en Montevideo (República Oriental del Uruguay) bajo el pseudónimo de H.Bustos-Domecq, hay un judío que va por la calle con un libro, sin prestar mayor atención a las masas ni a la fecha en un día de concentración ordenado por el general Perón. Es interceptado, sin que ni él ni los otros lo hayan querido ni buscado - presa del malhadado azar antes que de una caza deliberada-, por un grupo de descamisados que van a vitorear a Perón y a Evita en la ciudad Capital argentina. La sólo presencia de este muchacho joven, al que llaman 'cuatro ojos' porque usa lentes, los interpela: lo titean, lo golpean, finalmente lo matan. Este texto fue publicado en Uruguay, tierra de promisión del exilio argentino en tiempos de Rosas, y en tiempos de la "segunda tiranía", en expresión de los "contreras". En una novela del chaqueño Oscar Hermes Villordo, La otra mejilla ${ }^{7}$, publicada en la década "democrática" de 1980, un escuadrón de la muerte moralizante entra de noche en la vivienda de un pedicuro y lo mata por homosexual. La víctima se defiende, contra militares armados. Siempre el coraje es mejor. Pero inútil: lo matan, muere bañado en sangre Un patrón que seguirá la mayoría de las narraciones, literarias, periodísticas, cinematográficas, memorialistas, documentales, sobre la represión de las dictaduras de los '70: irrupción nocturna de bandas paramilitares armadas en domicilios particulares, secuestro, tortura en centro clandestino de detención, muerte de militantes o "subversivos" sobre cuyo pasado activo se informa poco, por importar sus muertes más que sus vidas.

11 2) El segundo rasgo singular en la política de estas narrativas se encuentra en la casi inescapable belleza atribuida a ese héroe (masculino) que es la víctima favorita, "viva moneda que nunca / se volverá a repetir" ${ }^{8}$ como dedica el poeta andaluz al Antoñito. A la figura del judío, Borges y Bioy la dotaron de hidalguía, belleza, idealismo, visión (y aumento de la visión por los lentes), y coraje. Contrasta con otras presentaciones del judío en la literatura, como las que les toca en la novela $L a$ bols ${ }^{9}$ del porteño Julián Martel (también seudónimo, de José María Miró) sobre el crac económico de 1890, o el relato "Una semana de holgorio"10 sobre el pogromo porteño de la "semana trágica" de 1919. Los autores son conocidos militantes contra el antisemitismo, pero no es ilícito preguntarse si las razones más fuertes por las que construyen así a la víctima sacrificial, que es un phármakon, un veneno y un remedio, no tienen su origen en la necesidad de conformar el relato de la víctima en una efigie también amonedada. Que ha hecho de esta galería de víctimas, un martirologio, un santoral, de íconos sexuales. Son jóvenes, son varones, son bellos. La juventud inocente, republicana, legal y revolucionaria asesinada por indios, negros, gauchos, montoneros, federales, peronistas o asesinos a sueldo de dictaduras cívico-militares. Pero, también pueden ser peronistas asesinados por anti-peronistas, como en la novela De Tales Cuales ${ }^{11}$ del mendocino Abelardo Arias: importa poco. La belleza del joven asesinado contrasta con la fealdad de los peronistas gordos, feos, ya entrados en carnes y en años, cornudos, que lo matan gratuita, brutal, aburridamente en el monstruoso cuento de Borges y Bioy.

Transparente alegoría: el martirio legitima a las élites a las cuales estas narrativas han restringido su reclutamiento de recursos humanos. El poema más famoso de Borges, 
"Poema conjetural"12, publicado en el diario conservador La Nación el día en que triunfó la revolución fascista argentina de 1943, despliega verso a verso un monólogo dramático atribuido a Francisco Narciso de Laprida, el jurista que en 1816 había leído la declaración de la Independencia argentina, en los últimos minutos antes de su muerte, cuando está huyendo en diligencia por el campo, perseguido por los montoneros rosistas: "Vencen los gauchos, los bárbaros vencen / Yo, Francisco Narciso de Laprida / cuya voz proclamó la Independencia / de estas crueles provincias / a cielo abierto yaceré entre ciénagas. / Al fin me encuentro con mi destino sudamericano." ${ }^{13}$ Para concluir con el momento mismo de la muerte por arma manual, con reminiscencia de la violación del por entonces centenario joven varón de Echeverría: el último verso del poema reza "El íntimo cuchillo en la garganta." 14

13 Los lectores rioplatenses que, como en la Antigüedad tardía los cultos egipcios alejandrinos del poema de Cavafy "Esperando a los bárbaros", se habían pasado la década de 1930 esperando a esos bárbaros, eran invitados a un décryptage, como dicen en France24. Y, precisamente como aquellos desciframientos relampagueantes que France24 día a día al mundo, no se le puede reprochar a éste ni falta de gusto por lo muy simple ni falta de preferencia por lo muy fácil: los bárbaros rosistas de 1838 eran los militares fascistas, que después serían peronistas, que habían dado el golpe de Estado en la Argentina de 1943.

En este monólogo narrativo de Borges, la matriz se proveía de un recurso nuevo, que con los años daría pruebas de su fertilidad: el esopismo, el retrotraer la escena a un tiempo anterior para así a la vez escaparle a la censura actual y explicarse el tiempo presente por una analogía. La época de Rosas resultará favorita, primero para representar el peronismo (al que se llamó 'la segunda tiranía'). Después, para representar a la dictadura cívico-militar de los '70s. Así en el film de María Luisa Bemberg, Camila $^{15}$, sobre un cura español y una aristócrata criolla fusilados por sus amores en tiempos de Rosas. En esta pareja de mártires idealistas, lleva la delantera el entonces hermoso Imanol Arias, porque para él es sacrílega la pasión, que además es él quien enciende en la entonces discreta Susú Pecoraro, y no al revés.

15 Entre las muchas objeciones que se podrían hacer a la matriz que estoy proponiendo para la cuenca del Plata, es la de ser un tanto argentino-céntrica y Borges-axial. Se podrían citar ejemplos y contra-ejemplos, pero eso ampliaría el campo de batalla sin hacer avanzar la polémica. Una estrategia lateral, que me ha ofrecido resultados propios, valgan lo que valieren, es acercarse a cómo se ha visto esta cuestión en el llamado Brasil do Mercosul, que pertenece a la región por derecho propio, en especial Río Grande do Sul y la tradición de la literatura gaúcha culta.

Cuando leemos novelas brasileñas del fin del siglo XX como Borges y los orangutanes eternos ${ }^{16}$ del portoalegrense Luis Fernando Verissimo - de la que he sido, para citar a la entrañable Lisa Block de Behar, "el intrépido traductor" al castellano- , o como Borges que amaba a Estela ${ }^{17}$ del rio-grandense Charles Kiefer, los hispanófonos regionales nos vemos forzados a reconocer que por pereza, o ignorancia supina, habíamos dado por sentado que el encuentro con Borges debía tener características centrales o básicas: aquellas que tuvo para nosotros. La presuposición, equivocada, es que la lectura de Borges, y del canon literario "culto" en castellano, tendría una lectura estético-literaria en primer término, y sólo cumplida esta recepción, seguiría una lectura "revisionista" política. 

de que Borges fuera un apóstata de toda ilusión del yo, un oficiante entusiasta en la liturgia fúnebre de la muerte del autor. El medio ambiente, estructuralista y post-, donde sonaba como soundtrack aquel réquiem, nos conminaba a dar por sabido y fechado un deceso sin cadáver. La sola lectura del Borges (2006) ${ }^{18}$ de Adolfo Bioy Casares registra el paladeo y regodeo de Borges, que antes que enmagrecer se revigoriza cada año, por la epopeya y por la épica del autor, poeta o fabulador.

En Borges que amaba a Estela $y$ otros dobles ${ }^{19}$, Kiefer inventa para Borges - sin proponérselo en estos términos, pero así resulta para nosotros- una vindicación (hasta una venganza) del Borges a contraluz (1989) ${ }^{20}$ de la argentina Estela Canto, y de la espiritual autora de este libro. Es un Borges erótico, acaso un tanto girardiano, que encuentra su doble o pareja en una escritora frustrada al momento de los acontecimientos, aunque memorialista avezada a posteriori. Y es una Canto que no está a la altura de las circunstancias -no las circunstancias intelectuales, aunque tampoco a la altura de estas -; sino sobre todo, y esta es la paradoja de Kiefer, amorosas. Borges a contraluz, según Kiefer, poco revela sobre Borges, pero es el testimonio y la prueba de una penosa, y en el fondo muy poco maliciosa, muy poco candorosa - sin ser por ello justificable o perdonable -, desorientación. Borges, revelado como victimario en el testimonio póstumo de una mujer humillada y despreciada, que había sido víctima callada a la fuerza por luchar por su orgasmo (en el Borges a contraluz de la propia Estela Canto), se vuelve victimaria por ejecutar esta póstuma vendetta contra un muerto (en la crónica-novela-ensayo de Kiefer). El autor gaúcho pone a las cosas en su lugar: la víctima, otra vez, es Borges.

En Borges y los orangutanes eternos, Verissimo llega al corazón de las tinieblas de esta matriz narrativa, y de la contribución fundamental, por canónica, de Borges a y en ella. Sin circunloquios, ni pasos previos perdidos, Verissimo va al íntimo cuchillo en la garganta de tantos desenlaces borgesianos. El encuentro cara a cara, fatal y letal, del varón letrado con los bárbaros que lo matan, con la lujosa barbarie asesina: su versión historia enérgicamente trágica de la Argentina y de su literatura desde El Matadero o "La Refalosa"21 de Hilario Ascasubi.

En Borges y los orangutanes eternos, novela policial, experimental, rigurosa y dépaysée, porque su acción transcurre en Buenos Aires, el gaúcho Verissimo hace la operación inversa que su paisano Kieffer: el destino sudamericano de Borges no es el de detective, mártir o legislador; no muere, sino que él es el matador: sin ser cuchillero, es el asesino. Borges mata, no muere.

21 Una vez más, importa menos a quién toca qué papel. El revisionismo de Verissimo es ratificación y no rectificación de la matriz narrativa. Pero en una línea peculiar, característica en especial de una tendencia mayoritaria en el siglo XXI, con el ascenso regional de gobiernos de centro-izquierda - el paralelismo es tan burdo como inescapable; el caso Maldonado, en tiempos de Mauricio Macri, fue un abandono de esta variación sobre el mismo tema, y un retorno a su forma y casting originarios.

En la década de 1970, en paralelo con los movimientos armados de liberación nacional otra comparación más forzosa que forzada -, la más absoluta de las inversiones había ocurrido en el interior de esta matriz narrativa sin embargo incólume: ahora el bárbaro es víctima y no victimario. En la nueva ficción empiezan a matar, pero en la nueva precariedad las élites intelectuales del Cono Sur están amenazadas de muerte o recambio. 

resucitar mejores? La bestia debe morir: si el 'otro' salvaje, hechiza lo hará con autocontrol, ni nos envenena ni nos posee ni nos convoca a la muerte. Acaba yéndose como quien se desangra. El protagonista se vuelve héroe sin que la victimización sea pre-requisito de heroicidad. El relato de la derrota digna y fatal como el de $L a$ decadencia de Occidente ya no seduce a los escritores de este frente para la victoria letrada.

Una lista adecuada o siquiera representativa de estos civilizados cuyos relatos puntualmente a los gauchos o bárbaros de la noche lateral (o liberal, o neoliberal, o dictatorial, o militar, o destituyente) de los pantanos que los acechaba y los demoraba sería larga, y acaso desprolija. Sólo ejemplificando, emulando sin panache a la remanida enciclopedia china de Borges-que inspira y ampara al no menos remanido Foucault de Las palabras y las cosas-, y ampliándonos como se amplió el Mercosur en aquella su perdida época de oro, algunos nombres y títulos. Ya en "El niño proletario" 22 de Osvaldo Lamborghini no son los populistas los que matan al elitista. En novelas del chileno Fuguet, del peruano Bayly, del boliviano Urrelo, de los argentinos Farré o Taborda, en películas como la venezolana Desde allá ${ }^{23}$, las argentinas Vil Romance ${ }^{24}$, Vikingo ${ }^{25}$, Agua y Sal ${ }^{26}$, El hombre de al lado ${ }^{27}$, Fase $7^{28}$, El ciudadano ilustre ${ }^{29}$ el golpe de fascinación y hostilidad, la guerra a muerte por el reconocimiento, ocurre, sin duda, pero, razonan los héroes de nuestro tiempo, ¿por qué morir nosotros, si podemos matar? Vendrá la muerte, pero tendrá mis ojos. Porque para todos tiene la muerte su mirada

Esa misma literatura argentina que, según la convincente sugerencia de David Viñas que, han oído, me ha convencido-, había nacido con una violación seguida de muerte, la del joven unitario a manos de los federales rosistas en El Matadero de Esteban Echeverría, la misma muerte que Bioy replica (y alegoriza en tiempos de peronismo) en el unitario que navega desde Uruguay para morir en Argentina en el "Homenaje a Francisco Almeyra"30, la de la escena inicial de Dar la cara ${ }^{31}$, film de Martínez Suárez, termina con otras violaciones y muertes. Sólo que, como Borges en "Emma Zunz" ${ }^{22}$, como los dos gaúchos, vale cambiar: los que matan antes morían, los que mueren antes mataban.

Es cierto que en "Emma Zunz" no son los más débiles los que mueren. Y aquí la heroína es una mujer, una Judith que se ha de vengar de un nazi (aunque signifique este relato, en forma especular, espectacularmente invertida, un cuestionamiento de la inanidad de las justificaciones del antisemitismo y aun del Holocausto). Esta Emma de Borges tiene que desfacer un entuerto que había sufrido su padre en Bagé. Es decir, en Rio Grande do Sul. En "El muerto" ${ }^{33}$ y en varios textos de Borges, Rio Grande do Sul es lugar de crímenes tanto más horrorosos e ignorados porque ocurren en el imperio de la anomia, en un mundo de contrabandistas y criaturas limítrofes que mueren según su ley, pero sin ley. Un más allá de las reglas y las normas: el otro lado del espejo de la tierra púrpura. Al otro lado de la uruguaya Rivera, en Sant'Anna do Livramento, empezó Hernández la composición de Martín Fierro ${ }^{34}$, según apunta Borges en un prólogo ${ }^{35}$ a este libro. Como el gaucho Fierro, el protagonista de esa narración en verso, entra en tierras indias, así el poeta gauchesco, para poder componer el poema, ha debido cruzar la frontera y entrar en dominios sin ley, los brasileños.

Como para mitigar el Edipo de Emma, había sido allí mismo, a esa ciudad riograndense de Bagé, donde Verissimo había ubicado a un psicoanalista, gaúcho ortodoxo, y freudiano estricto, que, auxiliado por su benjaminiana asistente Lindaura, resuelve los 
casos más difíciles. $O$ analista de Bagé es el libro más famoso de Verissimo, y uno de los libros más leídos de Brasil. Pero, para Juan Zunz, el analista fabricado en Porto Alegre llegó a destiempo a Bagé.

También con Santiago Maldonado, con cuya muerte hundiéndose en un río helado, huyendo a pie, terminan las ilusiones de Frente para la Victoria en estas narrativas, las utopías de batallas en las que triunfa el bien sobre el mal. En 2017, el "Caso Maldonado" polarizó la opinión pública argentina y chilena: la policía reprimió en la Patagonia a indios mapuches sin tierra y en el medio de la represión un activista pro-indígena (el joven Maldonado) desapareció. Su cadáver, sumergido en un río patagónico, sólo fue encontrado semanas después. El violento debate era dirimir con urgencia quién era víctima, quién victimario, quién salvaje, quién civilizado: ni eran fijos los actores, ni se sabía de antemano cuál papel generaría mayor rédito político.

El caso de Santiago Maldonado planteaba su alejamiento de inflexiones anteriores de la matriz. No mataba, moría. Pero su muerte, ¿hasta qué punto estaba desasociada por completo de fantasías eróticas de muerte heroica? inquirían unos y recusaban otros. Una vertiente de las más caudalosas de este flujo narrativo habían sido las fantasías en las cuales un protagonista se arranca de las garras de la vida cotidiana, mortal y castradora, con un sueño en Technicolor como el de del film El Mago de Oz en el que él transfigura esa misma muerte y castración en un escenario heroico.

Acaso el cuento más famoso de Borges sea "El sur" ${ }^{36}$, en el cual un modesto homo domesticus, que muere de septicemia porque de noche se golpeó la cabeza con una ventana abierta que no vio en la escalera sin luz de un inmueble, sueña en el lecho del hospital público que muere bajo otro cielo, luchando, en un duelo de hombre a hombre en un pueblo del campo (pero después vive, en forma degradada y degradante, pero completa y mortal, y consuma su muerte, a la intemperie y en la inhospitalaria provincia). En "La noche boca arriba" ${ }^{37}$, Cortázar recreó este sueño, con motociclistas y aztecas, pero en versión de final onírico y sin fuga del quirófano fatal; en "El otro cielo" 38 , lo recreó en un París de guillotinas y de un proto-surrealista Lautréamont; en "La señorita Cora" ${ }^{39}$, volvió a la cama de hospital, con un Wunderknabe (ya que no Wunderkind) víctima del bisturí mutilador, y de su madre.

31 En el relato de la muerte de Santiago Maldonado, unos leyeron la fantasía derrotista de la muerte soñada: el trasplante de medio de Santiago, joven blanco urbano, a tierra rural de indios, su ingreso en una comunidad mapuche, su participación en sus luchas. Esta versión de la historia que es básicamente la del Gobierno y los medios afines prosigue hasta una moraleja: la de Santiago era una pasión inútil. Los mapuches lo abandonaron, le soltaron la mano, cuando la gendarmería los perseguía porque había bloqueado una ruta nacional; sus hermanos indios no lo trataban fraternalmente, no le dijeron por dónde vadear un río helado; Santiago no sabía nadar y murió, ahogado, congelado.

Para la otra versión, virulentamente contradictoria, la de la oposición, Santiago encarnaba al héroe de la resistencia contra la dictadura militar, y era secuestrado, "desaparecido", torturado y asesinado por el terrorismo del Estado argentino-chileno, donde Piñera y Macri son la cara neo-liberal de los dictadores militares Pinochet y Videla.

Una desaparición forzada de persona por el Estado no ha sido demostrada, como tampoco lo ha sido el abandono de persona por los mapuches. Los antagonistas terminaron con el gusto insulso de una fake news descubierta o encubierta y finalmente 
extirpada de la virulencia y de la viralización. La matriz narrativa parecía haber entrado, por primera vez de lleno, en un tiempo muerto, pero no era difícil entrever el primer rayo de la aurora de su transfiguración y resurrección.

\section{NOTAS}

1. Adolfo Bioy Casares, Borges, Barcelona, Destino, 2006. Edición al cuidado de Daniel Martino.

2. Esteban Echeverría, El Matadero [1871], Buenos Aires, Losada, 1998

3. Estaban Echeverría, Elvira o la novia del Plata [1832], Alicante, Biblioteca Virtual Miguel de Cervantes, 2002.

4. Marcos Novaro, El caso Maldonado, Buenos Aires, Edhasa, 2017.

5. Federico García Lorca, "Muerte de Antoñito El Camborio" en Romancero gitano [1928], Obras Completas, Madrid, Aguilar, 1954.

6. Jorge Luis Borges y Adolfo Bioy Casares, "La fiesta del monstruo" [1947], Obras Completas II, Buenos Aires, Emecé, 1983.

7. Oscar Hermes Villordo, La otra mejilla, Buenos Aires, Sudamericana, 1986.

8. Federico García Lorca, "Muerte de Antoñito El Camborio", in Romancero gitano, op. cit.

9. Julián Martel, La Bolsa [1890], Buenos Aires, Losada, 2007.

10. Arturo Cancela, "Una semana de holgorio" [1919], in Tres relatos porteños, Buenos Aires, Espasa Calpe, 1946.

11. Abelardo Arias, De tales cuales, Buenos Aires, Sudamericana, 1973.

12. Jorge Luis Borges, "Poema conjetural" [1943], Obras Completas II, op. cit.

13. Ibid.

14. Ibid.

15. María Luisa Bemberg, dirección y guion, Camila, Argentina - Film estrenado en 1984.

16. Luis Fernando Verissimo, Borges y los orangutanes eternos [2000], Buenos Aires, Sudamericana, 2005. Versión castellana de Alfredo Grieco y Bavio.

17. Charles Kiefer, Borges Que Amava Estela E Outros Duplos, Río de Janeiro, Mercado Aberto, 1995.

18. Adolfo Bioy Casares, Borges, op. cit.

19. Charles Kiefer, Borges Que Amava Estela E Outros Duplos, op. cit.

20. Estela Canto, Borges a contraluz, Madrid, Espasa Calpe, 1989.

21. Hilario Ascasubi, "La Refalosa" [1843], in Jorge Luis Borges y Adolfo Bioy Casares, Poesía Gauchesca I, Buenos Aires, Fondo de Cultura, 1955. Cf. Josefina Ludmer, El género gauchesco: Un tratado sobre la patria, Buenos Aires, Sudamericana, 1988.

22. Lamborghini, Osvaldo, "El niño proletario" [1973], in Osvaldo Lamborghini, Novelas y cuentos, Barcelona, Ediciones del Serbal, 1988.

23. Lorenzo Vigas, dirección, Desde allá, Venezuela, 2016.

24. José Celestino Campusano, dirección y guión, Vil romance, Argentina, 2009.

25. José Celestino Campusano, dirección y guión, Vikingo. Argentina, 2010.

26. Alejo Taube, dirección y guión, Agua y sal, Argentina, 2012.

27. Gastón Duprat y Mariano Cohn, dirección y guión, El hombre de al lado, Argentina, 2009.

28. Nicolás Goldbart, dirección y guión, Fase siete, Argentina, 2010.

29. Gastón Duprat y Mariano Cohn, dirección y guión, El ciudadano ilustre, Argentina, 2016.

30. Adolfo Bioy Casares, Homenaje a Francisco Almeyra, Buenos Aires, Destiempo, 1954. 
31. José Martínez Suárez, dirección, y David Viñas, guión, Dar la cara, Argentina, 1962.

32. Jorge Luis Borges, "Emma Zunz" [1948] in El Aleph [1949], Obras Completas I, Buenos Aires, Emecé, , 1994.

33. Jorge Luis Borges, "El muerto" [1948] in El Aleph [1949], op. cit.

34. José Hernández, Martín Fierro [1872], Buenos Aires, Sur, 1962.

35. Jorge Luis Borges, "Prólogo" in José Hernández, Martín Fierro, op. cit.

36. Jorge Luis Borges, "El Sur" [1953], in "Artificios", Ficciones [1956], Obras Completas I, op. cit,

37. Julio Cortázar, "La noche boca arriba", in Final de juego, Buenos Aires, Sudamericana, 1956.

38. Julio Cortázar, "El otro cielo", in Todos los fuegos el fuego, Buenos Aires, Sudamericana, 1968.

39. Julio Cortázar, "La señorita Cora”, ibid.

\section{RESÚMENES}

La literatura de ficción de la cuenca del Plata independiente nace con un texto de la mayor urgencia política y de máxima calidad canónica: El Matadero (1838) de Esteban Echeverria, un relato de sobrio realismo crítico, de la violación masculina de un hombre por varios hombres en patota, un gang rape político seguido de muerte. Durante dos siglos, un principio constructivo literario inherente a esta matriz de narrativa política nacional, con su sistema de nítidas oposiciones hegemonizará toda la región en producciones literarias, periodísticas, cinematográficas, memorialistas y documentales. Que daban vox publica a quienes no tenían voz, y casi dos siglos después, ha podido mudar radicalmente la materia (a quién toca cada papel antagónico en la historia), pero ni el sentido ni la moraleja: la positividad toca a quien le toque el lugar de la víctima.

La littérature de fiction indépendante est née au bassin du rio de la Plata avec un texte de la plus grande urgence politique et de la plus haute qualité canonique : la nouvelle El Matadero (1838) d'Esteban Echeverria. Le récit, d'un réalisme critique souple et sobre, du viol d'un homme par plusieurs hommes en gang devient l'allégorie d'un viol collectif politique suivi de mort. Pendant deux siècles, un principe littéraire constructif inhérent à cette matrice du récit politique sudaméricaine, avec son système d'oppositions claires, deviendra hégémonique dans toute la région dans les productions littéraires, journalistiques, cinématographiques, mémorialistes et documentaires. Elles ont donné la vox publica à ceux qui auparavant n'avaient pas de voix. Même si près de deux siècles plus tard, la donne a radicalement changé (à savoir qui est qui dans l'histoire), ni le sens ni la morale n'ont bougé : peu importe qui sera la victime, elle s'attire indéfectiblement l'adhésion du lecteur.

\section{ÍNDICE}

Palabras claves: literatura sudamericana, literatura argentina, Violencia política en América Latina, urgencia y escritura de la urgencia, Echeverría (Esteban), Lamborghini (Osvaldo), caso Maldonado

Mots-clés: littérature sud-américaine, littérature argentine, violence politique en Amérique latine, urgence et écriture de l'urgence, Echeverría (Esteban), Lamborghini (Osvaldo), affaire Maldonado 
AUTOR

ALFREDO GRIECO Y BAVIO

Museo de la Fundación CAPS, Asunción del Paraguay 